\title{
The challenges of new information technologies applied to public transport and rail operations
}

\author{
P. Vuaillat \\ Semaly, France
}

\begin{abstract}
The management of information has been associated to the movements of goods and passengers right since the origin of the transportation business. Fast couriers were galloping flat out ahead of caravans and merchants in order to announce important people and prepare fair trades. Cables and telegraphs were channelling bips across oceans or plains as soon as ships or trains were steaming out of harbours or railway stations. Process of information has improved more and more along one and a half century of joint technological progress and development of transportation and information technologies. Their fates are totally interrelated. Although NTI have fundamentally changed from hyper centralized processes toward delocalized processors and from rigid procedures to customized applications the needs remain the same: to inform passengers and traders and to support operators ${ }^{\mathrm{TM}}$ fleet, staff and maintenance management. Rail and Public Transport operations remain largely based today upon the principles imposed decades ago by existing technologies and when there were still no planes or cars to compete with trains or ships. The major challenge remains today to rethink the way trains and public transport are operated in terms of clients $^{\mathrm{TM}}$ expectations and company management. NTI (driverless, train control, new signalling, etc.) had demonstrated that they can bring more safety and more reliability as well as more capacity to the operation of existing infrastructures. NTI had although proved to be able to accompany the social change within operating companies. There is still a lot to do for the best of clients and staff by attending the right needs. Some issues can be managed at any time along the life of a transportation system (just by improving systems along with technology evolution without impact on infrastructures). Others shall come right at concept design of new projects like opportunities to optimize quality and costs (capex + opex).

Keywords: NTI, new technology information.
\end{abstract}




\section{Introduction}

Although this topic could lead to a vaster overview of the various situations we propose in this short paper to focus onto two different study cases (mass transit and heavy rail):

- Extension of line B in Lyons with comparative study between conventional signalling and conversion to driverless (similar to existing line D).

- Compatibility between TVM 300 (early 80's) and ERTMS standard for extensions of High Speed Lines en France.

\section{Lyons line B Extension}

\subsection{Objectives}

Attend traffic demand increase.

Fix obsolescence issues on key components.

Stay within acceptable costs.

Improve operation and maintenance.
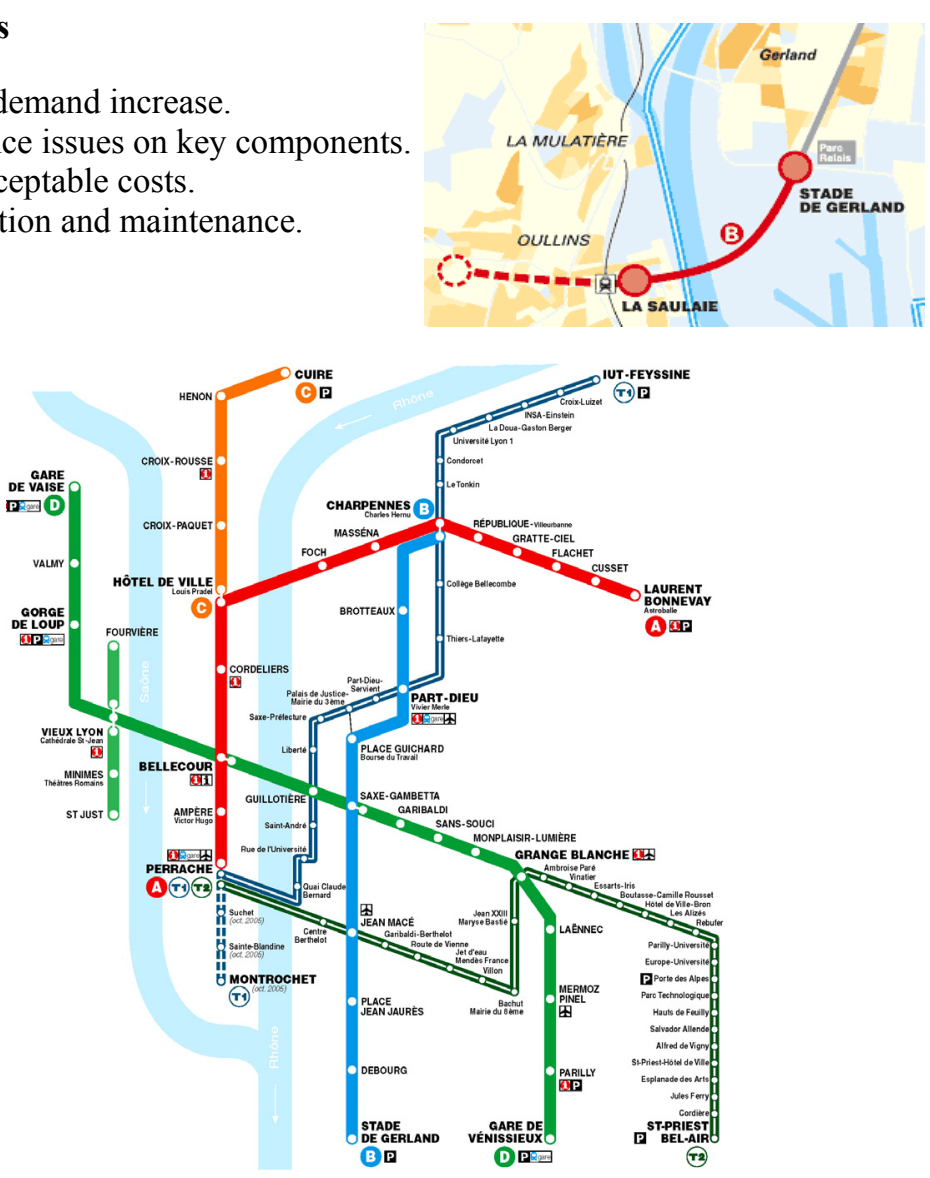


\subsection{Conclusion}

- Very high cost if train extension from 2 to 4 cars.

- Headway very close to the 90 s system limitation on line D with two car trains (no problem with extension to three cars train).

- $\quad$ No need to buy new MAGGALY compatible ATO with extension from 2 to 3 car trains.

- $\quad$ Problem at Charpennes terminus with three car trains.

\subsection{Charpennes terminus case}

Headway system limitation $=113 \mathrm{~s}$.

Practical headway due to terminus configuration $($ driver shift $)=141 \mathrm{~s}$.

Possible headway with additional staff at station $=130$ s ( 34 s stop at station).

Possible solutions:

Station regulation with additional staff.

Driverless conversion (no more staff consraint).

Extension to four car trains (169s headway).

Construction of a new stockage area (9M€ - 2001).

\subsection{Train transfer from one line to another}

\subsubsection{Line A to line $B$ (and vice versa) at Charpennes}

No problem (currently used for line B train going to depot), including exceptional transfers of line D trains via Saxe for major repairs at the depot La Poudrette.

\subsubsection{Line D to line at Saxe Gambetta}

Not possible for nominal operation $>>$ systems are not compatible and line D train (driverless) have major speed limits under fully manual drive (no ATP):

- Advantage of a unique Control Centre:

Better coordination between lines on the entire network (especially in case of crippled mode).

Staff optimisation.

- Disadvantage of a unique Control Centre:

Existing CC configuration is very sensitive to major disruption.

Extension impact on existing $\mathbf{C C}$

Technically feasible.

Total refurbishing necessary if line B conversion to driverless (more supervision).

Current space sufficient (including new security supervision centre).

\section{Lines $A$ and $B$ technical description}

Analogic ATO through frequence based speed coding.

Track circuit based train localisation. 
Conventional railway signalling in addition.

Headway:

- $\quad 90$ s nominal on ATO and 120s on manual operation (ATP).

- $\quad 25 \%$ margin on operation, i.e. 110 s on ATO.

- Nominal $113 \mathrm{~s}$ at Charpennes.

Train regulation through acceleration rate and maximum speed (only 2 codes out of 6 currently used).

New ATO would improve operation speed.

\subsection{Lines A and B obsolescence}

Study done when extending line B to Gerland stadium.

Minor changes on wayside equipments.

Spare parts until 20.20.

Technical documentation sufficient for remanufacturing if needed.

Complete change necessary on board equipments (conversion to numerical).

In case of extension to Oullins, a new obsolescence study is needed if existing system extended too.

\section{Line D ATO technical description}

$\underline{\mathrm{ATO}}$

- Moving block.

- Mat based bi-directional numerical transmission.

Conventional signalling along the entire line.

No possibility to run full operation speed when manually driven.

Headway

- $\quad 80$ s nominal Theorique.

- 90 s operation.

Limitation

Not possible to run unequipped train on it.

\subsection{Line D ATO obsolescence}

Maximum effort done at operator level (in full cooperation with owner) to manage knowledge and possibility to improve marginally the system.

Spare parts until 2020 (life cycle).

Technology is obsolete and re-manufacturing impossible without new detail studies.

Development platform not operating beyond 2007.

Very high estimated cost for redevelopment of a MAGGALY ATO compatible with existing. 


\subsection{Prospective}

\subsubsection{Extension of current ATO}

4.2.1.1 Line A No need of change before 2020/2025.

4.2.1.2 Line B Necessary re-manufacturing of wayside and onboard equipments and development of interface equipments with new rolling stock.

Acceptable solution until 2020/2025.

4.2.1.3 Line D Demand imposes heavy changes (extension to 3 or 4 car train).

Urgent decision due to near complete obsolescence or development platform.

Current system able to stay until 2020 if capacity issue is solve otherwise (3 car trains or constraints on feeding bus or trolleybus lines).

\subsection{Prospective}

\subsubsection{Driverless and ATO}

With conventional ATO, driver role is mostly limited to watching (station and tunnel) and keeping knowledge of train management and evacuation whenever necessary.

Existing on-the-shelf supplier systems offer both options (manual drive or driverless) $>>$ minor extra costs.

Extra costs are incurred by additional systems or equipments to be fitted to accompany driverless (PSD, fall detection, sensitive edge door, etc).

\subsection{Prospective}

\subsubsection{A unique ATO on the network?}

- Better for testing and commissioning,

- Better for operation,

- A simplified CC,

- High train flexibility and transfer,

- Better for maintenance,

- Staff optimisation,

- $\quad$ Simplified knowledge management,

- $\quad$ Reduced stock of spare parts.

\subsection{Prospective}

\section{Maggaly: is it a base for a new ATO?}

Limited to Lyons (unique manufacturing and obsolescence management borne by Lyons alone.

No maintenance borne by suppliers.

Need to redevelop $100 \%$ software and hardware.

Operator is happy with the system (for he knows it) although availability could be improved (mainly due to lack of PSD) >>improvement works in progress. 
A system with lots of limitation (especially when comes the need to operate unequipped trains).

\subsubsection{Conclusion}

MAGGALY experience is very rich but MAGGALY ATO cannot be used as a basis for a new ATO.

\subsection{Prospective}

\subsubsection{A new ATO on Line A\&B?}

Not compulsory within the Oullins extension time scale (2012) but could:

Improve operation speed.

Allow driverless implementation whenever needed.

Start development of an "ATO network" maintenance concept.

\subsection{Prospective}

\subsubsection{Migration on Line A\&B}

Wayside

Implement two parallel systems.

Find space in technical rooms.

On-board

1. Very difficult to implement double systems (space problems).

2. Need to make it two-in one.

\subsubsection{Proposed scenario}

3. Implementation of wayside equipments.

4. Validation with prototype train.

5. Progressive migration of train with 2 systems.

NB: this scenario does not work with MAGGALY.

\subsection{Prospective}

\subsubsection{Migration on Line D}

Similar space problems wayside and on board and no way to run an unequipped train on a MAGGALY infrastructure.

Proposed scenario

1. Night tests section by section.

2. Migration when operation is stopped on the line ( $\sim 1$ month).

\subsection{Prospective}

\subsubsection{Estimated out of Nuremberg and Hong Kong feedback}

\subsubsection{Lines $A$ and $B$}

- Line A: between 20 and $25 \mathrm{M€}$.

- $\quad$ Line B: between 15 and 20M€. 
- $\quad$ Line C: between 10 and $15 \mathrm{M€}$.

- $\quad$ Line D: $\sim 30 \mathrm{M€}$.

East Kowloon Line (source MTRC Hong Kong) $10 \mathrm{~km}, 7$ stations and 20 existing trains (ATO SACEM type line A RER Paris).

\subsubsection{Cost of conversion to driverless:}

Wayside and on-board migration: $5 \mathrm{M} €$.

Rolling stock modification: $2 \mathrm{M} €$.

Implementation/tests/commissioning: $3 \mathrm{M} €$.

U3 (source VAG Nuremberg).

$15 \mathrm{~km}, 16$ stations, new trains with driverless ATO, mixed operation with old trains on common $\mathrm{U} 2 / \mathrm{U} 3$ section.

Driverless implementation costs: 14.2M€ (2001).

U2 (source VAG Nuremberg).

$10 \mathrm{~km}$ of existing line, 11 stations, new driverless fitted trains to replace old trains, mixed operation with unfitted old trains.

Driverless implementation costs: 21.8M€ (2001).

This experience is the first in the world of a conventional line converted into driverless.

\subsubsection{Migration to driverless in Lyons}

4.9.2.1 Lines A and B Modification of wayside, on-board and transmission equipments.

Implementation of PSD or fall detection devices.

Modification of curved platforms (not directly linked to driverless conversion).

Access control of tunnels.

New access to technical rooms without walking the tunnels.

Implementation of test sections.

Flat rubber-tyred wheel detection (both rolling and guiding wheels).

\section{High Speed Rail / Compatibility TVM 300 and ERTMS standard}

\subsection{How to make existing trainsets running on new HSL without modifications of on-board equipments}

The question is similar with TVM 430 and ERTMS (HSL East European).

\subsubsection{Technical feasibility}

Questions: how to develop a system based on current technology to transmit TVM 300 signals?

\subsubsection{Existing architecture}

- TVM 300 (LGV Atlantique).

Interlocking and TVM are separated. Interlocking supplies messages for speed coding and EM-TVM supplies fail safe messages. 


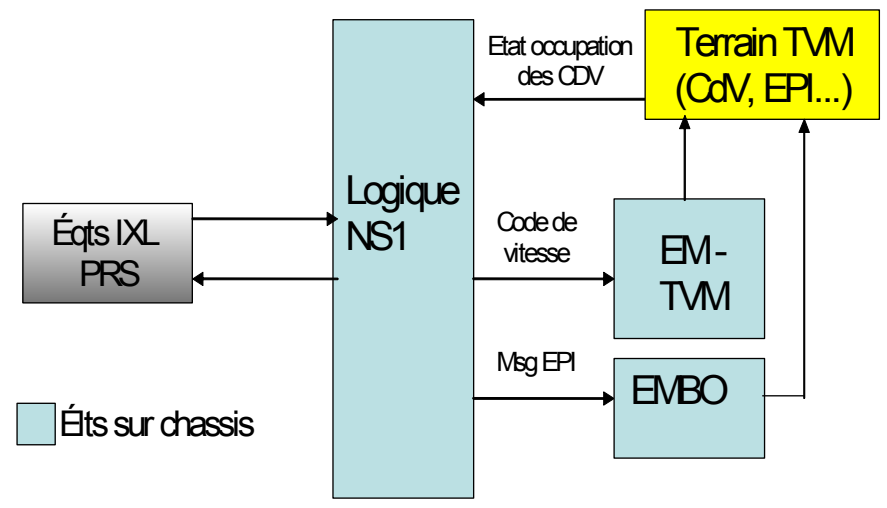

- $\quad$ SEI / TVM 430 (HSL méditerranée, HSL EE).

\subsubsection{Integrated solution}

Interlocking and TVM are integrated in the SEI.

Safety is ensured by internal re-reading of the information received from track circuit.

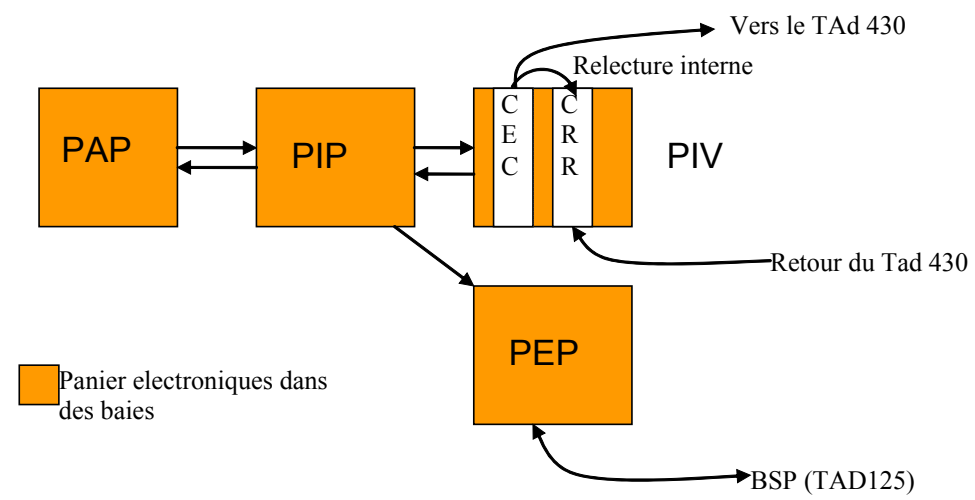

\subsubsection{Electro-magnetism proofness}

- Standard have considerably changed since first HSL. TVM 300 is not compatible today.

\subsection{Proposition of mixed architecture}

Presentation:

- SEI / TVM 300 integrated solution: Adaptation de l'architecture existante SEI / TVM 430

- $\quad$ PAI-NG - TVM 300 separated solution: Adaptation of existing PRS + EM-TVM300 solution 


\subsubsection{Comparison of 2 solutions}

5.2.1.1 Solution SEI More compact (less cabling):

- Save space and design time frame,

- Ease testing and maintenance (a lot of maintenance information are available, specially on track circuit)

\subsubsection{Solution PAI-NG}

- Non proprietary solution

- Cheaper

\subsubsection{Risk analysis}

\begin{tabular}{|l|lc|ll|}
\hline & \multicolumn{2}{|l|}{ SEI / TVM integrated solution } & $\begin{array}{l}\text { PAI-NG TVM separated } \\
\text { solution }\end{array}$ \\
\hline HSL Atlan & $\begin{array}{l}\text { Conception: } \\
\text { Obsolescence: }\end{array}$ & low medium & $\begin{array}{l}\text { Conception: low } \\
\text { lobsolescence: }\end{array} \quad$ low \\
\hline HSL Med & Conception: & high & Conception: & high \\
\hline
\end{tabular}

In both scenarios, the costs of developments for new solutions are much lower than the retrofit of the entire HS Train fleet.

\section{Conclusion}

As Teilhard de Chardin showed it 60 years ago ("The future of Mankind") the major change of the 20th Century (and subsequent challenges) is not technological. Evolution and Revolution in Technologies just had to adapt to the new goals of Mankind: we are not any more spending most of our energy to expand all over the Globe; we are now obliged to develop our creativity to living closer and closer together both regionally and worldwide with the growing need of organizing our joint future on a shrinking planet that will look every day smaller and smaller. The World of Rail Public Transport (either Urban or Intercity) is at the heart of this Planet re-shaping: bigger and bigger cities with a need for safer and faster increasing exchanges between cities.

NTI are at the heart of it and drive the new challenges by introducing major changes in the way the key players behave:

- new operating principles and major changes within operating companies (lesser differences between drivers and support staff).

- interoperability (operators are lesser and lesser stakeholders).

- new relations between operators and users/clients (mainly in terms of information and safety).

\section{Reference}

[1] Pierre Teilhard de Chardin, L'Avenir de l'Homme, 1959. 